\title{
PREVALÊNCIA DO ESTREPTOCOCO DO GRUPO B EM GESTANTES E SUA RELAÇÃO COM A INFECÇÃO NEONATAL
}

\section{MATERNAL COLONIZATION RATE OF GROUP B STREPTOCOCCUS AND ITS RELATION TO NEONATAL INFECTION}

\section{PREVALENCIA DEL ESTREPTOCOCO DEL GRUPO B EN MUJERES EMBARAZADAS Y SU RELACIÓN CON LA INFECCIÓN NEONATAL}

\author{
Aline Baraldi Higashi ${ }^{1}$, Rosely Erlach Goldman ${ }^{2}$, Irany Rocha da Silva ${ }^{3}$
}

\begin{abstract}
RESUMO
Objetivo: Conhecer a prevalência e os resultados maternos e perinatais causados pela colonização estreptococo do grupo B em gestantes. Método: Estudo descritivo e retrospectivo desenvolvido a partir de dados secundários obtidos no livro de registro e prontuários clínicos das mães e recém-nascidos. A amostra foi composta por 130 prontuários do binômio mãe/recém-nascido. Resultados: A prevalência da colonização materna pelo estreptococo do grupo B foi de 193 (11,24\%). Sete $(5,4 \%)$ recém-nascidos evoluíram com o diagnóstico de sepse neonatal, porém com resultado de hemocultura negativa. Foram utilizados os testes de Mann-Whitney e da razão de Verossimilhança para as análises dos grupos de interesse. Conclusão: A prevalência da colonização pelo estreptococo do grupo B entre as gestantes avaliadas foi em concordância com os valores encontrados na literatura. Enfatizamos que o rastreamento deve ser incentivado nos protocolos de atenção ao pré-natal.

Descritores: Streptococcus agalactiae. Antibioticoprofilaxia. Cuidado Pré-Natal. Assistência Perinatal.
\end{abstract}

\begin{abstract}
Objective: To understand the predominance and the maternal and perinatal results caused by Streptococcus agalactiae colonization of group B in pregnant women. Method: Descriptive and retrospective study developed from secondary data of registry book and mothers/newborns' medical records. The sample consisted of 130 medical records of the mothers/newborns. Results: Maternal colonization rate of Streptococcus agalactiae was 193 $(11,24 \%)$. The intrapartum antibiotic prophylaxis for the Streptococcus B was performed in 86 pregnant women $(66,2 \%)$. Seven newborns $(5,4 \%)$ evolved with the diagnosis of neonatal sepsis, however, all had a negative blood culture results. Mann-Whitney tests and likelihood estimation were used for analysis of interest groups. Conclusion: The maternal colonization rate of Streptococcus agalactiae was accordance with the values found in the literature. We emphasize that the screening should be encouraged in prenatal care protocols.

Descriptors: Streptococcus agalactiae. Antibiotic prophylaxis. Prenatal care. Perinatal care

\footnotetext{
${ }^{1}$ Enfermeira Obstetra pela Universidade Federal de São Paulo. Programa de Residência Uniprofissional em Enfermagem Obstétrica. Enfermeira Obstetra no Hospital Santa Lucinda - Sorocaba, São Paulo.

${ }^{2}$ Enfermeira Obstetra no HMLMB - São Paulo.

${ }^{3}$ Professora Adjunta na Escola Paulista de Enfermagem, Universidade Federal de São Paulo - Departamento Saúde da Mulher.
} 


\section{RESUMEN}

Objetivo: Conocer la prevalencia y los resultados maternos y perinatales causados por la colonización por estreptococo del grupo B en las mujeres embarazadas. Método: Estudio descriptivo y retrospectivo desarrollado a partir de datos secundarios en el libro de registro clínico y registros médicos de madres/recién nacidos. La muestra consistió en 130 historias clínicas de la madre / recién nacido. Resultados: La prevalencia de colonización por estreptococo del grupo B materna ocurrió en 193 (11,24\%). Las profilaxis antibiótica intraparto para estreptococo B, se realizó en 86 mujeres embarazadas $(66,2 \%)$. Siete $(5,4 \%)$ evolucionaron con el diagnóstico de sepsis neonatal, sin embargo, todas presentaron resultados de los cultivos de sangre negativo. Mann-Whitney y la razón de verosimilitud fueron utilizados para el análisis de los grupos de interés. Conclusión: La prevalencia de colonización por estreptococo del grupo B en mujeres embarazadas se evaluó de acuerdo con los valores encontrados en la literatura. Hacemos hincapié en que el examen de rutina para la detección del estreptococo del grupo B debería fomentarse en los protocolos de atención Descriptores: Streptococcus agalactiae. Profilaxis antibiótica. Atención prenatal. Atención perinatal.

\section{INTRODUÇÃO}

Os estudos sobre a prevalência da colonização pelo estreptococo do grupo B (EGB) ou Streptococcus agalactiae refletem a preocupação com as complicações associadas a este agente. Trata-se de um diplococo gram-positivo que tem como reservatório, nos humanos, o trato gastrointestinal. ${ }^{1}$ No ciclo gravídico puerperal a colonização pode acarretar infecções do trato urinário, corioamnionite, endometrite, sepse ${ }^{1,2}$, bem como, comprometer a evolução da gestação causando trabalho de parto prematuro, abortamento, morte fetal intrauterina e rotura prematura das membranas ${ }^{3}$ e forte associação com a infecção materna puerperal.

No período neonatal, a doença estreptocócica é definida como precoce quando as manifestações clínicas ocorrem nos primeiros seis dias após o nascimento. Os estudos mostram alta prevalência, acometendo dois terços dos casos, sendo aproximadamente $80 \%$ nos primeiros dias de vida. ${ }^{2,4}$ Já as manifestações da doença definida como tardia aparecem entre sete e 90 dias após o nascimento, sendo que as formas mais comuns nos recém-nascidos são a sepse, pneumonia e meningite. ${ }^{4}$

O principal fator de risco para a ocorrência da infecção pelo EGB é a colonização do trato genital materno; as taxas de mortalidade neonatal são mais expressivas em pré-termos ${ }^{2,5}$, aproximadamente $20 \%$, chegando a $30 \%$ em idade gestacional menor ou igual a 33 semanas quando comparadas a recémnascidos de termo, que não ultrapassam 2 a $3 \% .^{5}$ 
Anteriormente à introdução da antibioticoprofilaxia no momento do parto, os índices de doença de início precoce variavam de 2 a 3 por 1.000 nascidos vivos. Hoje, devido ao rastreamento realizado no terceiro semestre da gestação, a incidência diminuiu para $0,34-0,37$ casos por 1.000 nascimentos vivos. ${ }^{5}$ Em 1996, foi elaborado pelo Centers for Disease Control and Prevention (CDC) em colaboração com outras entidades como o American Congress of Obstetricians and Gynecologists (ACOG), a primeira proposta para a prevenção da infecção materno-fetal, baseada na pesquisa de fatores de risco para EGB. ${ }^{6}$ Ela foi revista e reelaborada em 2002, sendo estabelecida como estratégia profilática essencial a investigação rotineira do EGB em secreção vaginal e anal entre 35 e 37 semanas de gestação. $^{7}$

A última publicação do $\mathrm{CDC}$, em 2010, mantém a estratégia do rastreamento no pré-natal e o uso de antibiótico para profilaxia em: mulheres com a bactéria isolada na urina em qualquer momento da gestação; cultura de $s w a b$ vaginal e/ou anal com resultado positivo na gestação atual e filhos anteriores que desenvolveram doença pelo EGB. Em casos de resultado da cultura não realizada ou desconhecida, indica-se também a profilaxia para trabalho de parto prematuro; ruptura prematura de membranas ovulares superior ou igual a 18 horas, temperatura intraparto maior ou igual a $38{ }^{\circ} \mathrm{C}$ e rastreamento positivo no pré-natal. ${ }^{5}$

O Royal College of Obstetricians and Gynaecologist (RCOG), em sua última atualização do guia para prevenção da doença de início precoce causada pelo EGB de 2012, não recomenda o rastreio bacteriológico de rotina no pré-natal, justificando que não há comprovação do custo-efetividade da realização do procedimento. ${ }^{8}$ No Brasil, não há nenhum consenso ou recomendação técnica. O Ministério da Saúde em seu último manual de Atenção ao Pré-Natal de Baixo Risco 2012 não preconiza o rastreamento na rotina pré-natal do EGB até que se comprovem maiores evidências do seu benefício. ${ }^{9}$ Entretanto, a Secretaria de Saúde do Estado de São Paulo, através do seu Manual Técnico do Pré-natal e Puerpério de 2010, mantém a recomendação sobre a realização do procedimento. ${ }^{10}$ Estabelecida também, no Encarte Técnico de Assistência Obstétrica e Perinatal, Rede de Proteção a Mãe Paulistana, da Secretaria Municipal da Saúde de $2007 .^{11}$

Diante deste contexto, o estudo teve como objetivo conhecer a prevalência da colonização pelo estreptococo do grupo $\mathrm{B}$ e avaliar os resultados maternos e 
perinatais causados pelo mesmo agente em gestantes atendidas em uma maternidade do Município de São Paulo.

\section{MÉTODOS}

Estudo descritivo retrospectivo, com abordagem quantitativa, realizado no Hospital Maternidade Leonor Mendes de Barros, em São Paulo. A coleta de dados ocorreu de junho de 2014 a setembro de 2014, em duas etapas: análise das informações contidas no Livro Registro de Coleta para cultura de EGB, a fim de avaliar a prevalência do EGB; e análise dos prontuários dessas puérperas e recémnascidos que tiveram o resultado da cultura para EGB positiva durante o pré-natal.

O protocolo da instituição oferece a coleta para cultura de secreção vaginal e anal para o EGB às gestantes de 35 a 37 semanas de gestação e realiza a antibioticoprofilaxia no momento da internação para o parto nos seguintes casos: gestantes com cultura de secreção vaginal positiva; gestantes com EGB isolados na urina em qualquer concentração durante o decorrer da gestação; e antecedente de recém-nascido acometido por doença causada pelo EGB. Em casos nos quais o resultado da cultura não é conhecido, recomenda-se antibioticoprofilaxia quando existir algum dos fatores de risco que incluem: trabalho de parto em gestação com menos de 37 semanas; ruptura das membranas ovulares a 18 horas ou mais; temperatura materna intraparto maior ou igual a $38^{\circ} \mathrm{C}$; e óbito neonatal anterior por sepse ou hipertensão pulmonar nas primeiras 48 horas. ${ }^{11}$

$\mathrm{O}$ antibiótico de escolha para a profilaxia é a Penicilina Cristalina, na dose de 5 milhões UI endovenosa como dose de ataque, seguida de 2,5 milhões UI endovenosa $(\mathrm{EV})$ de 4 em 4 horas até o momento do parto. Em casos de alergia, pode-se optar pela Eritromicina EV 500mg de 6 em 6 horas ou Clindamicina 900mg EV de 8 em 8 horas. A administração de duas doses de qualquer antibiótico é considerada profilaxia adequada. ${ }^{11}$

A coleta da amostra para o rastreio de EGB foi realizada por uma enfermeira responsável pelo setor, sendo utilizados dois swabs estéreis: um para a cultura vaginal, obtida com a introdução de um swab através do introito vaginal de modo a realizar a coleta de amostra do terço distal da vagina sem uso de espéculo; e um segundo swab, para a cultura anorretal, obtida através do orifício anal para a coleta de amostra da parede distal do reto. ${ }^{10-1}$

Cada um dos dois swabs foi inoculado em tubo de ensaio individual devidamente rotulado, contendo meio de cultura específico e encaminhado para o laboratório Associação Fundo de Incentivo 
à Pesquisa (AFIP), sendo responsável pela leitura e laudo do exame.

Os critérios de inclusão foram os registros do Livro de Coleta para cultura do estreptococo B e os prontuários clínicos das mulheres e recém-nascidos com resultado de cultura positiva para a bactéria no momento do pré-natal, no período de janeiro de 2012 a janeiro de 2014 que corresponde ao momento da coleta de EGB no setor de pré-natal. Foram excluídos os prontuários clínicos das gestantes que não foram assistidas no momento do parto na referida instituição.

$\mathrm{Na}$ primeira etapa da coleta de dados através da análise das informações contidas no Livro Registro de coleta para cultura de EGB, foram identificadas 193 gestantes com cultura positiva para o EGB, portanto a segunda fase da coleta de dados ocorreu em torno dos 193 prontuários clínicos.

Durante a busca e avaliação dos 193 prontuários clínicos das puérperas com resultado de cultura positiva para $\mathrm{o}$ estreptococo B e dos seus recém-nascidos. Foram excluídos 63 prontuários, sendo 54 referentes às gestantes que não realizaram o parto na instituição, seis prontuários não foram encontrados e três com dados incompletos. Portanto, a amostra foi composta por 130 prontuários clínicos.

$\mathrm{Na}$ primeira etapa da coleta de dados, as informações coletadas do Livro Registro foram registradas em formulário específico, sendo as variáveis analisadas a "idade gestacional pela ultrassonografia no momento da coleta do exame" e o "resultado da cultura para o EGB".

$\mathrm{Na}$ segunda etapa, os dados coletados dos prontuários clínicos foram registrados em formulário específico, e as variáveis estudadas relacionavam-se a características sociodemográficas: "idade"; "situação conjugal"; "cor de pele autodeclarada"; "escolaridade e condição de atividade"; História reprodutiva: "número de gestações"; "paridade" e "abortos"; "história anterior de recémnascido pré-termo" e "história anterior de morte perinatal”; Gestação atual: “idade gestacional calculada pela ultrassonografia no momento do parto"; "realização do prénatal" e "número de consultas"; "prática da antibioticoprofilaxia para a colonização por estreptococo B com identificação do antibiótico" e o "número de doses"; "presença de rotura de membranas ovulares" e "quanto tempo de rotura"; "morbidade materna" (febre materna intraparto, infecção do trato urinário, corioamnionite, endometrite, sepse e meningite) e dados do puerpério: "coleta de exames laboratoriais do recémnascido"; "exames laboratoriais do recémnascido com resultados alterados"; 
"morbidade recém-nascido" (pneumonia, meningite ou sepse neonatal precoce); "antibioticoterapia no recém-nascido"; “confirmação da infecção pelo estreptococo B no recém-nascido"; "hemocultura" e "óbito neonatal"; "dias de internação neonatal" e "dias de internação da puérpera".

Os dados foram tabulados em planilhas do Microsoft Excel® ${ }^{\circledR} \quad$ e exportados para o Statistical Package for the Social Sciences, versão 20, para Windows® e realizada análise descritiva. Nas comparações entre os grupos de interesse, dias de internação neonatal por sepse neonatal precoce e entre a variável número de doses de antibioticoprofilaxia em relação aos exames laboratoriais dos recém-nascidos alterados, utilizou-se o teste de Mann-Whitney e o teste da razão de Verossimilhança, respectivamente, com intervalo de confiança de $95 \%$.

O desenvolvimento do estudo atendeu as normas nacionais e internacionais de ética em pesquisa envolvendo seres humanos, aprovado pelo Comitê de Ética em Pesquisa da Universidade Federal de São Paulo, sob número 655.820/2014, atendendo a todas as recomendações da Resolução 466/2012, do Conselho Nacional de Saúde.

\section{RESULTADOS}

Das 1.717 amostras coletadas de estreptococo do grupo B, 193 obtiveram resultados de cultura positiva para a bactéria, sendo a prevalência de acometimento da colonização materna pelo ECG de 11,24\%.

Em relação à idade gestacional, $1.334(77,7 \%)$ gestantes realizaram o exame com a idade gestacional adequada, conforme a recomendação dos protocolos do Ministério da Saúde e da Secretaria de Saúde do Estado de São Paulo e 383 gestantes $(22,3 \%)$ coletaram o exame com idade gestacional inapropriada, sendo 281 antes das 35 semanas de gestação e 102 após a $37^{\mathrm{a}}$ semana.

Em relação aos dados sociodemográficos, a média da idade foi de 29,07 anos (DP 8,03), mínimo de 15 a máximo de 47 anos, 33,1\% casadas, 58,5\% brancas, $56,9 \%$ cursaram o ensino médio e $57,7 \%$ não economicamente ativa (Tabela 1).

Tabela 1. Características sociodemográfica das mulheres com cultura positiva para o estreptococo do grupo B - São Paulo SP, Brasil, 2014.

\begin{tabular}{lll}
\hline Variáveis & $\mathrm{N}$ & $\%$ \\
\hline Situação & & \\
conjugal & & \\
Solteira & 39 & 30,0 \\
Casada & 43 & 33,1 \\
União & 42 & 32,3 \\
estável & & \\
Divorciada & 3 & 2,3 \\
Viúva & 1 & 0,8 \\
Sem & 2 & 1,5 \\
Registro & &
\end{tabular}


Cor da Pele

\begin{tabular}{|c|c|c|}
\hline Branca & 76 & 58,5 \\
\hline Parda & 16 & 12,3 \\
\hline Preta & 28 & 21,5 \\
\hline Amarela & 8 & 6,2 \\
\hline Sem & 2 & 1,5 \\
\hline \multicolumn{3}{|l|}{ Registro } \\
\hline \multicolumn{3}{|l|}{$\begin{array}{l}\text { Escolaridad } \\
\mathrm{e}\end{array}$} \\
\hline Analfabeta & 1 & 0,8 \\
\hline Ensino & 30 & 23,1 \\
\hline \multicolumn{3}{|l|}{ Fundamenta } \\
\hline Ensino & 74 & 56,9 \\
\hline \multicolumn{3}{|l|}{ Médio } \\
\hline Ensino & 8 & 6,2 \\
\hline \multicolumn{3}{|l|}{ Superior } \\
\hline Sem & 17 & 13,1 \\
\hline \multicolumn{3}{|l|}{ Registro } \\
\hline \multicolumn{3}{|l|}{$\begin{array}{l}\text { Condição } \\
\text { de atividade }\end{array}$} \\
\hline $\begin{array}{l}\text { Não } \\
\text { economica } \\
\text { mente ativa }\end{array}$ & 75 & 57,7 \\
\hline $\begin{array}{l}\text { Economica } \\
\text { mente ativa }\end{array}$ & 53 & 40,8 \\
\hline $\begin{array}{l}\text { Sem } \\
\text { registro }\end{array}$ & 2 & 1,5 \\
\hline Total & 130 & 100 \\
\hline
\end{tabular}

Em relação à história reprodutiva, a média foi de 2,39 gestações (DP 1,37), sendo o mínimo de uma e máximo de seis; quanto à paridade, a média foi de 1,06 (DP 1,15), mínimo de um e o máximo quatro partos; a respeito de abortamento, a média foi de 0,33 (DP 0,65), sendo o mínimo de zero e o máximo de três abortos; quanto a história anterior de parto prematuro, 129 $(99,2 \%)$ negam e cinco $(3,8 \%)$ relatam morte perinatal anterior.

A média da idade gestacional foi de 39,24 semanas pela ultrassonografia (DP 1,03), sendo 7,21 (DP 2,42) a média do número de consultas pré-natal, mínimo de uma e o máximo de 15 consultas.

No momento do parto, a profilaxia para o estreptococo B foi realizada em 86 parturientes $(66,2 \%)$, sendo a penicilina cristalina o antibiótico mais utilizado (80\%-93,0\%). Em relação ao número de doses, apenas uma dose foi administrada em mais da metade das parturientes (49\% $-57,0 \%)$. Em relação à rotura de membranas ovulares $(65 \%-50,0 \%)$, houve rotura com a média de tempo de 259,78 minutos (DP 404,62).

A presença do EGB não causou nenhuma morbidade nas puérperas, sendo a média de internação hospitalar de 2,94 dias (DP 0,98), mínimo de um dia e máximo de sete dias.

Quanto aos dados dos recém-nascidos, verificou-se que $104 \quad(80,0 \%)$ foram submetidos à coleta de exames laboratoriais e $20(19,2 \%)$ com resultados alterados, sendo o exame de Proteína C Reativa alterado em 12 recém-nascidos $(60,0 \%)$. Foi necessário o uso de antibioticoterapia, gentamicina e ampicilina, em oito recém-nascidos (6,2\%). Desses, em que foram administrados os antibióticos, sete $(5,4 \%)$ evoluíram com o diagnóstico de sepse neonatal precoce e um com diagnóstico de 
asfixia perinatal grave, encefalopatia, hipóxia isquêmica, síndrome convulsiva e insuficiência renal com desfecho ao óbito (Tabela 2).

Em nenhum dos casos de sepse neonatal precoce foi confirmada a infecção pelo estreptococo B ou por qualquer outro patógeno. Todos apresentaram resultado de hemocultura negativa, e a média dos dias de internação neonatal foi de 3,28 dias e materna de 2,94 dias. O mínimo de um dia para recém-nascido e mãe, e o máximo de 10 e sete dias, respectivamente.

Tabela 2. Caracterização dos recémnascidos segundo a coleta de exames laboratoriais, presença da antibioticoterapia e morbidade - São Paulo SP, Brasil, 2014.

\begin{tabular}{lll}
\hline Variáveis & $\mathrm{N}$ & $\%$ \\
\hline $\begin{array}{l}\text { Exames } \\
\text { laboratoriais }\end{array}$ & & \\
$\begin{array}{l}\text { Hemograma } \\
\text { (HMG) }\end{array}$ & & 5,0 \\
HMG e & 2 & 10,0 \\
Proteína C & & \\
Reativa & & \\
(PCR) & & 60,0 \\
PCR & 12 & 25,0 \\
PCR, HMG & 5 & \\
e líquido & & \\
cefalorraqui & & \\
diano & & \\
(LCR) & & \\
Presença da & & \\
antibioticote & & \\
rapia & & \\
Não & 122 & 63,8 \\
Sim & 8 & \\
Espectro & & \\
Gentamicin & 8 & \\
a e & & \\
Ampicilina & &
\end{tabular}

Morbidade

\begin{tabular}{lll} 
Não & 122 & 93,8 \\
Sim & 8 & 6,2 \\
\hline Total & 130 & 100 \\
\hline
\end{tabular}

Os dados da Figura 1 mostram que a média dos dias de internação dos recémnascidos com diagnóstico de sepse neonatal precoce apresentam maior tempo de internação quando comparado aos recém-nascidos saudáveis (p-valor < $0,001)$.

Figura 1. Dias de internação neonatal por sepse neonatal precoce, São Paulo SP, Brasil, 2014.

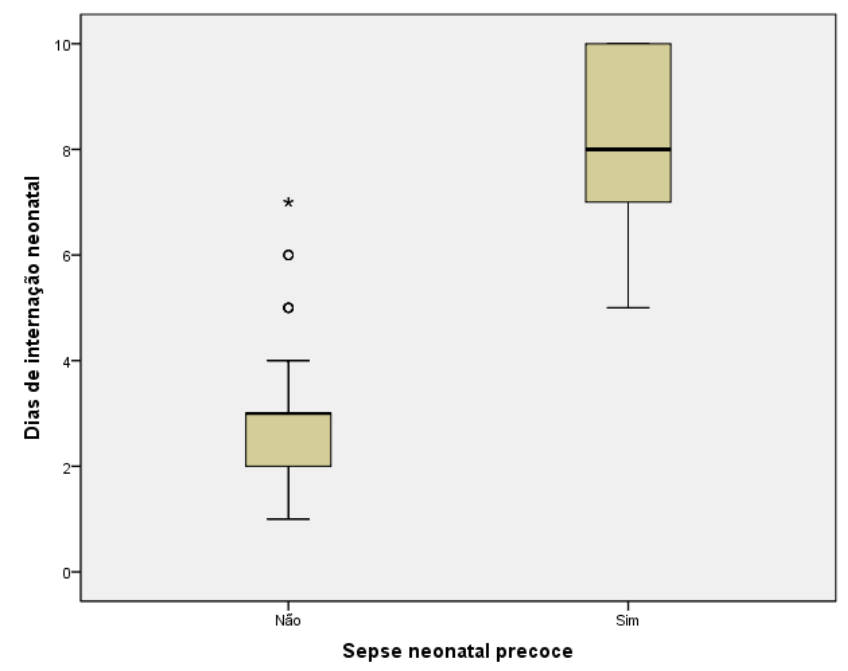

A figura 2 demonstra a comparação entre a variável "número de doses de antibioticoprofilaxia" em relação aos exames laboratoriais dos recém-nascidos alterados. Nota-se que $91,0 \%$ dos recémnascidos das parturientes que receberam apenas uma dose de antibiótico apresentaram alterações nos exames 
laboratoriais da proteína $\mathrm{C}$ reativa (PCR), hemograma ou líquido cefalorraquidiano. Em contrapartida, apenas 9,0\% dos recémnascidos das mães que realizaram a profilaxia intraparto correta evidenciaram alterações nos exames laboratoriais.

Figura 2 - Doses de antibioticoprofilaxia e exames alterados nos recém-nascidos, São Paulo SP, Brasil, 2014.

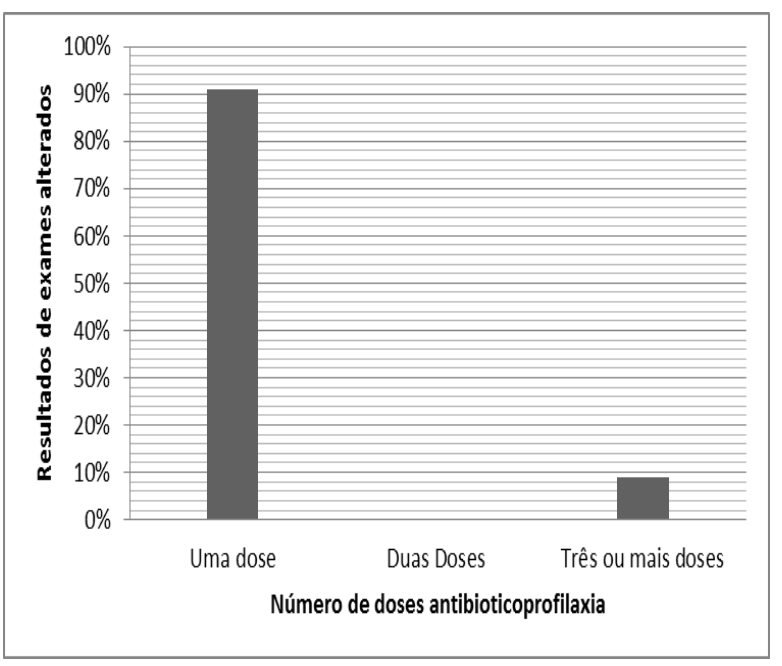

\section{DISCUSSÃO}

A prevalência da colonização materna pelo EGB foi de $11,24 \%$, em concordância com os valores encontrados na literatura entre $10 \%$ a $30 \%{ }^{5,12}$, sendo a taxa média mundial de $20 \% .^{13}$ Estudos realizados nas diversas regiões do Brasil - como Nordeste, Sul e Centro-Oeste encontraram prevalência nas gestantes de $17,4 \%, \quad 23,1 \%$ e $15,2 \%$, respectivamente. $^{14-16}$ Uma pesquisa realizada pela Fundação Oswaldo Cruz, no Rio de Janeiro, com 3.929 mulheres, revelou a taxa de 4,7\%; no entanto, subestima-se o baixo número devido às técnicas microbiológicas do laboratório e do momento de coleta no pré-natal. ${ }^{17}$

Os dados brasileiros são relativamente escassos, pode-se considerar a taxa média de colonização materna no país em torno de $15 \%$, colocando o Brasil em uma situação de risco, pois é provável que exista um grande número de mães colonizadas, bem como taxa de infecção neonatal precoce sem serem identificadas. $^{14}$ Para garantir que 0 rastreamento no pré-natal seja custoefetivo, a prevalência de colonização materna deve superar os $10 \%{ }^{14}$

No que tange à idade gestacional no momento da coleta do swab para pesquisa do agente, $77,7 \%$ das gestantes o realizaram conforme a diretriz da Secretaria de Saúde do Estado de São Paulo. ${ }^{10-1}$ No entanto, $22,3 \%$ das gestantes coletaram o exame com idade gestacional inapropriada, sendo 281 antes das 35 semanas de gestação e 102 após a 37 semana.

A coleta da cultura para o estreptococo B realizada precocemente, ou seja, antes de 35 semanas de idade gestacional, não garante colonização materna até o momento do parto ${ }^{18}$, podendo ocorrer intervenções desnecessárias, bem como a não 
administração do antibiótico em casos precisos, já que a sensibilidade e especificidade da cultura são melhores se realizadas de quatro $^{18}$ a cinco semanas antes do parto. ${ }^{19}$

Se realizada a coleta tardia, após a $37^{a}$ semana de idade gestacional, é provável, no momento do parto, que o resultado da cultura não esteja em com a parturiente, dificultando a conduta médica. As causas para o rastreamento ser realizado em idade gestacional inadequada podem ser advindas de erros no cálculo da idade gestacional, bem como do desconhecimento ou da errônea interpretação dos protocolos de assistência pelo profissional. $^{18}$

Diversos possíveis fatores de risco para a colonização pelo EGB foram encontrados na literatura, tais como idade materna, paridade, estado conjugal, escolaridade, renda mensal e até mesmo tabagismo; no entanto os resultados dos estudos são, por enquanto, inconclusivos. $^{14,18}$

A média de consultas pré-natal realizada foi de 7,2 consultas, atendendo ao número mínimo de seis consultas exigido pelo Ministério da Saúde. ${ }^{9}$ O Hospital em que foi realizado o estudo é referência para o pré-natal de alto risco; por conseguinte, essas gestantes foram atendidas na Unidade Básica de Saúde e encaminhadas para o serviço de alto risco devido a algum problema identificado, o que mostra a funcionalidade e eficácia do sistema de referência e contrarreferência do Sistema Único de Saúde do país. ${ }^{9}$

A antibioticoprofilaxia foi administrada em $66,2 \%$ das parturientes, sendo a penicilina cristalina o antibiótico mais utilizado (93\%), resultado esperado por ser o medicamento de primeira escolha, conforme o Manual da Secretaria Municipal da Saúde de São Paulo. É notável que muitas mulheres não foram contempladas com a profilaxia antibiótica intraparto $(33,8 \%)$. Tal fato pode ser justificado por algumas parturientes chegarem ao Hospital em fase tardia do trabalho de parto e por casos de cesárea eletiva, em que não se faz necessária a administração do antimicrobiano. ${ }^{5}$

Apenas uma dose de antibiótico foi administrada em mais da metade das parturientes $(57,0 \%)$, o que pode ser um fator determinante para as infecções neonatais, pois a proteção do antimicrobiano ocorre se a droga estiver em circulação no organismo materno por quatro ou mais horas. ${ }^{5}$ Para a eficácia da profilaxia antibiótica intraparto (PAI) ser em torno de $90 \%$ na prevenção da infecção neonatal precoce, é imprescindível que sejam completadas as horas recomendadas. ${ }^{5,19}$ 
Os principais fatores de risco para a infecção neonatal precoce encontrados na literatura são: trabalho de parto prematuro, colonização materna por EGB, ruptura prematura de membranas $\geq 18$ horas, febre intraparto $\geq 38^{\circ} \mathrm{C}$, bacteriúria por EGB na gestação atual e infecção prévia neonatal por EGB. ${ }^{5,19}$ A presença desses fatores aumenta cerca de seis vezes e meia a probabilidade de morbidade neonatal precoce por EGB em comparação com gestantes que não apresentam nenhum fator de risco. ${ }^{19}$

Metade das mulheres apresentou rotura prematura de membranas ovulares, com tempo médio de 259,78 minutos. Apesar de não ser um fator de risco, devido ao tempo médio de rotura ser menor que o estimado, aumentaria a suscetibilidade de contaminação dos fetos por causa da ascensão da bactéria até a cavidade amniótica

Dos oito recém-nascidos que necessitaram do uso de antimicrobianos logo após o nascimento, sete tiveram o diagnóstico de sepse neonatal precoce clínica, com resultado de hemocultura negativa. Dessas mães, três fizeram o uso de uma dose de penicilina e foi identificada rotura de membranas ovulares por 40, 45 e 108 minutos, sendo que, em quatro parturientes, não foram realizadas a PAI e também não havia o diagnóstico de rotura de membranas.

A taxa de sepse neonatal precoce de $5,4 \%$ é preocupante e o uso de antibiótico pela parturiente pode influenciar a negatividade do exame de hemocultura, o que também acontece se a coleta for realizada após o início da antibioticoterapia nos recém-nascidos. ${ }^{5}$ Mesmo sendo considerado padrão-ouro, apenas $30 \%$ dos casos apresentam hemocultura positiva; deste modo, não se pode excluir completamente uma possível infecção neonatal causada pelo EGB.

Os recém-nascidos com diagnóstico de sepse neonatal precoce ficaram internados mais dias na unidade de terapia intensiva neonatal se comparados com os saudáveis, gerando maiores gastos para o governo, sobrecarga de trabalho e até superlotação da unidade. Isso, possivelmente, poderia ser evitado se a PAI fosse realizada adequadamente.

Recentemente, um estudo publicado pela Biblioteca Cochrane avaliou os efeitos da administração de antibióticos em mulheres colonizadas pelo EGB sobre a sepse neonatal precoce e óbito neonatal por infecção, concluindo aparente redução da infecção neonatal, mas ainda não há evidências suficientes para definir qual é a melhor estratégia para a prevenção, a antibioticoprofilaxia intraparto para todas as mulheres 
colonizadas ou apenas as com fatores de riscos identificados. ${ }^{20}$

\section{CONCLUSÃO}

A prevalência da colonização pelo estreptococo do grupo B entre as gestantes avaliadas foi em concordância com os valores encontrados na literatura. Considerando que o escaneamento no prénatal se torna custo-efetivo quando a prevalência de infecção materna supera os $10 \%$, não há dúvidas de que o rastreamento é benéfico e deve ser incentivado nos protocolos de atenção ao pré-natal.

Este estudo apresentou como limitação as anotações incompletas realizadas pelos profissionais nos prontuários clínicos.

Apesar dos resultados negativos dos exames de hemocultura dos recémnascidos, a taxa de infecção neonatal encontrada no estudo foi alta e merece atenção já que não se pode excluir, totalmente, contaminação pelo EGB. Sendo assim, levantou-se a importância da continuação da profilaxia antibiótica intraparto para manter e ainda melhorar o controle da contaminação neonatal.

Portanto, faz-se necessária a realização de estudos controlados, com maior número de mulheres e recémnascidos a fim de determinar protocolos de orientação no Brasil para o rastreamento do EGB no pré-natal, bem como para a profilaxia antibiótica intraparto.

\section{Agradecimentos}

Agradecemos ao Hospital Leonor Mendes de Barros que possibilitou a realização deste estudo.

\section{REFERÊNCIAS}

1. Areal A, Nunes S, Moreira M, Faustino MA, Cardoso L, Sá C. Infecção perinatal por Streptococcus agalactiae pode ser evitada: Prevalência da colonização em parturientes no Hospital São Marcos, factores de risco e a sua relação com a infecção perinatal. Acta Pediatr Port 2010:41(1):16-21

2. Pogere A, Zoccoli CM, Toboutti NR, Freitas PF, Acampora AJ, Zunino JN. Prevalência da colonização pelo estreptococo do grupo B em gestantes atendidas em ambulatório de pré-natal. Rev Bras Ginecol Obstet. 2005;27(4):174$80 . \quad$ doi: 10.1590/S010072032005000400003.

3. Senger FR, Alves IA, Pellegrini DCP, Prestes DC, Souza, EF, Corte ED. Prevalência da colonização por Streptococcus Agalactiae em gestantes atendidas na Rede Pública de Saúde de Santo Ângelo - RS. RECI. 2016; 6(1). doi: 10.17058/reci.v6i1.6272.

4. Schuchat A. Epidemiology of Group B Streptococcal Disease in the United States: Shifting Paradigms. Clin Microbiol Ver. 1998;11(3):497-513.

5. Centers for Disease Control and Prevention (EUA). Prevention of Perinatal Group B Streptococcal Disease: Revised Guidelines from CDC.MMWR; 2010;59 (RR-10):1-32.

6. Centers for Disease Control and Prevention (EUA). Prevention of perinatal group B streptococcal disease: a public health perspective. MMWR;1996;45 ( RR7):1-24.

7. Centers for Disease Control and Prevention (EUA). Prevention of perinatal group B streptococcal disease: revised 
guidelines from CDC. MMWR;2002;51( RR-11):1-22.

8. Royal College of Obstetricians and Gynaecologist. The Prevention of Earlyonset Neonatal Group B Streptococcal Disease. Green-top Guideline $\mathrm{N}^{\mathbf{0}} 36$. $2^{a}$ edição. United Kingdom: Royal College of Obstetricians and Gynaecologist;2012.

9. Ministério da Saúde (Brasil). Cadernos de atenção básica: Atenção ao Pré-natal de baixo risco. Série A. Normas e Manuais Técnicos Cadernos de Atenção Básica. Brasília: Ministério da Saúde; 2012.

10. Secretaria de Estado da Saúde de São Paulo (São Paulo), Coordenadoria de Planejamento em Saúde. Assessoria Técnica em Saúde da Mulher. Atenção à gestante e à puérpera no SUS - SP: manual técnico do pré-natal e puerpério. São Paulo: SES/SP; 2010.

11. Secretaria Municipal da Saúde (São Paulo), Programa Mãe Paulistana, Secretaria da Saúde. Coordenadoria de Desenvolvimento de Programas e Políticas de Saúde- CODEPPS. Encarte Técnico assistência Obstétrica e Perinatal. Rede de Proteção a Mãe Paulistana. São Paulo: SMS/SP; 2007.

12. Hsiu WY, Hsiao CL, Peng HY, Chyong $\mathrm{HH}$, Wu SH, Lon YT, et al. Group B Streptococcal Infection in Taiwan: Maternal Colonization and Neonatal Infection. Pediatr Neonatol. 2011;52(4):190-95. doi: 10.1016/j.pedneo.2011.05.008

13. Barcaite E, Bartusevicius A, Tameliene R, Kliucinskas M, Maleckiene L, Nadisauskiene R. Prevalence of maternal group B streptococcal colonisation in European countries. Acta Obstet Gynecol Scand. 2008;87(3):260-71. doi: 10.1080/00016340801908759.

14. Oliveira MV, Teles MF, Viana TA. Prevalência e fatores de risco associados à colonização por Streptococcus Agalactiae em gestantes atendidas no Hospital Municipal Esaú Matos em Vitória da Conquista - BA. C\&D. [internet]. 2013. [citado em 03/04/2015]; 2013; 6(1):172-
184.

Disponível

em:

http://200.223.150.195/revista/index.php/m emorias/article/view/197/146.

15. Kiss FS, Rossato JS, Graudenz MS, Gutierrez LLP. Prevalência da colonização por Streptococcus agalactiae em uma amostra de mulheres grávidas e não grávidas de Porto Alegre, estado do Rio Grande do Sul. Sci Med. [internet]. 2013. [citado em 03/04/2015];2013;23(3):169$174 . \quad$ Disponível em: http://revistaseletronicas.pucrs.br/ojs/index .php/scientiamedica/article/view/14265.

16. Pires TS. Colonização pelo estreptococo B: prevalência, fatores de risco, características fenotípicas e genotípicas em mulheres no terceiro trimestre de gestação atendidas no serviço de referência materno infantil de Goiânia, Goiás [Mestrado em Medicina Tropical e Saúde Pública]. Goiás: Universidade Federal de Goiás; 2009.68p.

17. Costa NDVL, Carvalho M, Pone SM, Júnior SCG. Gestantes colonizadas pelo Streptococcus do grupo B e seus recémnascidos: análise crítica da conduta adotada no Instituto Fernandes Figueira, Fundação Oswaldo Cruz. Rev Paul Pediatr. 2010;28(2):155-61. doi:10.1590/S010305822010000200005.

18. Função JM, Narchi NZ. Pesquisa do estreptococo do Grupo B em gestantes da Zona Leste de São Paulo. Rev Esc Enferm USP. 2013;47(1):22-9. doi: 10.1590/S0080-6234201300010000

19. Oliveira VMM, Moraes Filho OB. Solicitar ou não cultura para estreptococo do grupo B no final da gestação? Femina. 2009;37(7):361-65.

20. Smaill FM. Intrapartum antibiotics for Group B streptococcal colonisation. Cochrane Database of Systematic Reviews. In: The Cochrane Library. 2014; 9 (1). doi:10.1002/14651858.

Recebido em: 27/10/2015

Aprovado em: 11/07/2016

Publicado em: 31/07/2016 